\title{
The effect of interbeds on distribution of incremental oil displaced by a polymer flood
}

\author{
Hou Jian ${ }^{1 *}$, Du Qingjun², Lu Teng ${ }^{1}, Z^{2}$ ou Kang and Wang Rongrong ${ }^{1}$ \\ ${ }^{1}$ School of Petroleum Engineering, China University of Petroleum, Dongying, Shandong 257061, China \\ ${ }^{2}$ School of Geo-resources and Information, China University of Petroleum, Dongying, Shandong 257061, China \\ (C) China University of Petroleum (Beijing) and Springer-Verlag Berlin Heidelberg 2011
}

\begin{abstract}
This paper discusses the effect of influencing factors on the distribution of incremental oil displaced by a polymer flood (extra-displaced oil) using numerical reservoir simulation. These factors include the location, area and permeability of a thin low-permeability interbed, and the perforation location relative to the interbed. Simulation results show the locations from where the incremental oil was displaced by the polymer solution. The interbed position from the oil formation top affects the location of extra-displaced oil. The interbed area has a slight influence on the whole shape of extra-displaced oil. Larger interbed area leads to higher partition extent of extra-displaced oil. Higher vertical permeability of interbeds contributes to worse partition extent of extra-displaced oil and the partition effect disappears if the ratio of vertical to horizontal permeability is more than 0.05 . The perforation location relative to the interbed affects polymer displacement efficiency, and also has a significant effect on the distribution of extra-displaced oil in polymer flooding.
\end{abstract}

Key words: Reservoir simulation, polymer flooding, interbed, remaining oil distribution

\section{Introduction}

Polymer flooding has been successfully applied as an enhanced oil recovery (EOR) method for decades in many oilfields such as the Daqing and Shengli Oilfields in China (Wang et al, 2002, 2003; Chang et al, 2006; Sun, 2006; Hou et al, 2008). An oil reservoir is often separated into several independent fluid flow units by thin low-permeability or impermeable layers or interbeds present in the reservoir, leading to complicated oil-water flow which has a seriously influence on the distribution of the remaining oil. More oil will be recovered from the reservoir in the polymer flooding operations which take place after the original water flooding. So it is important to determine the location of oil that can be recovered in the polymer flooding operations. The existence of interbeds would heavily affect the distribution of oil left behind after polymer flooding (Chen and Sun, 2003; Du et al, 2006; Hou, 2007; Jupiter, 2010). Taking as an example the $\mathrm{Ng} 3$ unit in the Zhongyi area, Gudao oil field, a pilot area for polymer flooding, we have studied the effect of interbeds and the perforation location with respect to the interbeds on the oil displaced by polymer flooding with numerical reservoir simulation technology.

*Corresponding author. email: houjian1005@yahoo.com.cn Received September 24, 2010

\section{Extra-displaced oil saturation in polymer flooding}

Based on the Ng3 unit in the Zhongyi area, Gudao oilfield, where polymer flooding has been used as an enhanced oil recovery technique, we built a typical numerical reservoir model which reflects the geological characteristics of this unit. The formation top depth of the model was $1,190 \mathrm{~m}$. This model consists of two oil layers, which are isolated by an impermeable layer (permeability: 0). There are 12 productive intervals showing a fining-upward succession in each layer (in which the size of grains grade from coarse at the base to fine at the top). The two oil layers have an average effective thickness of 9.0 and $4.5 \mathrm{~m}$ and an average horizontal permeability of 2 and $1 \mu \mathrm{m}^{2}$, respectively. The vertical permeability variation coefficient among the intervals in each layer is 0.5 . In each interval, the vertical permeability is one tenth of the horizontal permeability. The original oil saturation was 0.68 and the oil viscosity $40 \mathrm{mPa} \cdot \mathrm{s}$.

In this model, a staggered line-drive pattern, with a well spacing of $260 \mathrm{~m} \times 300 \mathrm{~m}$, was used to develop the reservoir. Because of symmetry, simulations were performed on only a quarter of a five-spot well pattern (Fig. 1).

In order to describe the incremental oil displaced by a polymer flood and the factors influencing it, Hou et al (2010) proposed the concept of extra-displaced oil saturation in polymer flooding, which is defined as the difference between the oil saturation after water flooding and the oil saturation 


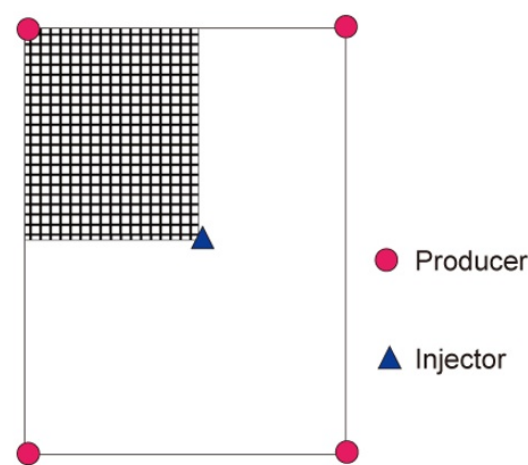

Fig. 1 The well pattern and simulation domain

after polymer flooding under the same simulation conditions. That is,

$$
\Delta S_{\text {oed }}=S_{\text {ow }}-S_{\text {op }}
$$

where $\Delta S_{\text {oed }}$ is the extra-displaced oil saturation; $S_{\text {ow }}$ is the oil saturation after water flooding; $S_{\mathrm{op}}$ is the oil saturation after polymer flooding.

Here, the same simulation conditions mean that the simulation runs were terminated at $90 \%$ water cut of produced fluids in both water flooding and polymer flooding operations.

The vertical distribution of oil left behind after water flooding and the extra-displaced oil in polymer flooding are shown in Figs. 2 and 3, respectively. Owing to the profile modification by polymers, the oil displaced by polymer flooding is mainly concentrated in the middle-lower part of the remaining oil-rich zones near the injection well after water flooding, which takes on an inclined spindle shape.

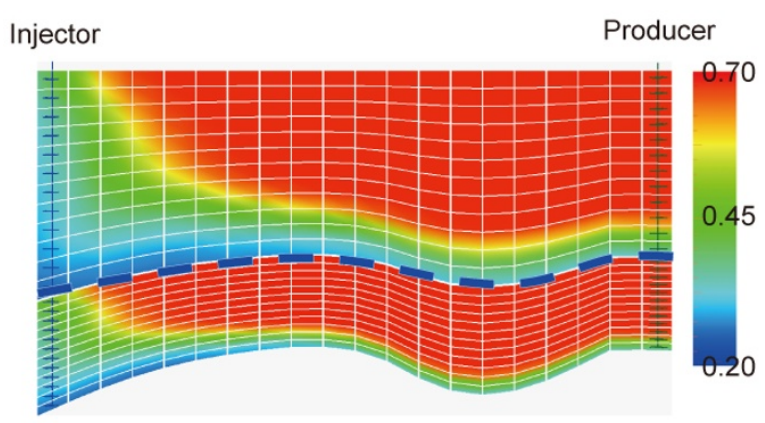

Fig. 2 The vertical distribution of oil left behind after water flooding

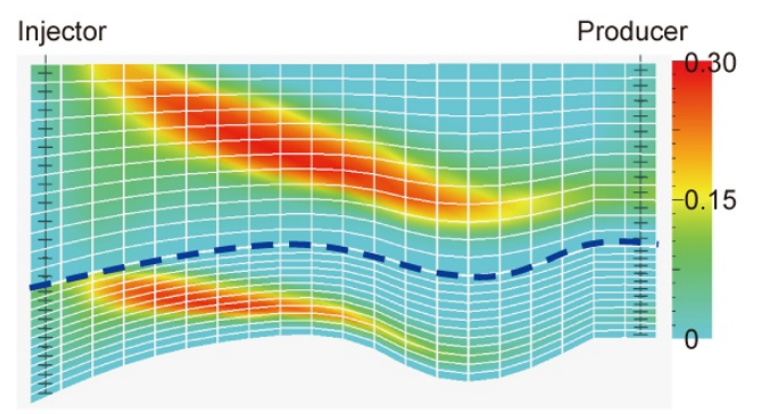

Fig. 3 The vertical distribution of oil displaced by polymer solution (extra-displaced oil)

\section{The effect of the interbed}

Interbeds which are distributed continuously between the injection and production wells will subdivide a thick oilbearing layer into several flow units, so it is easy to form many water flooded zones. However, if the interbed is not continuously distributed in the reservoir, the water injected into the reservoir easily flows downwards due to gravity. More discontinuous interbeds will lead to complicated movement and distribution of water and oil. The interbed reduces the effect of gravity and capillary force, so the interbed is helpful to improve the vertical sweep efficiency of water injected into the fining-upward and thick oil-bearing layers, while it disadvantages the displacement of the oil trapped in the lower part of the coarsening-upward oil layers. As a result, the oil displacement becomes more complex.

Three different types of geological models, including homogeneous, fining-upward, and coarsening-upward models were established. For these models, the interbeds, taking on the same shape as the simulation zone, are located between the injection and production wells. The interbed is located at $4.5 \mathrm{~m}$ from the formation top and its area is $50 \%$ as large as that of the simulation zone.

In order to show more clearly the effect of the interbed on extra-displaced oil distribution in polymer flooding (oil mobilized by polymer injection), Fig. 4 through Fig. 7 and Fig. 9 show the simulation results of the first layer, i.e. the layer overlying the impermeable layer (blue dashed line in Figs. 2 and 3).

\subsection{The effect of the interbed location}

The interbed location influences the distribution of oil left behind after water flooding and also affects the oil displaced by the polymer flood. The remaining oil distribution after water flooding and the extra-displaced oil distribution in polymer flooding were discussed independently on the homogeneous, fining-upward, and coarsening-upward models with a variation coefficient of 0.5 when the interbed is located at $2.25,4.50$, and $6.75 \mathrm{~m}$ from the formation top, respectively. Numerical simulation results show that the interbed location influences slightly the oil recovery performance, but it has a significant effect on the distribution of oil left behind after water flooding and the distribution of extra-displaced oil in polymer flooding.

Fig. 4 shows the distribution of oil trapped in the upper layer after water flooding. The solid lines in Figs. 4-7 and Fig. 9 represent the interbed present in the upper oil layer. The vertical flow of injection fluids is constrained due to the lowpermeability interbed. During water flooding, those adjacent intervals above the interbed are water flooded, leading to the partition of the remaining oil by the interbed. The oil in the top of the reservoir and that below the interbed is difficult to displace by water. The influence of the interbed position from the top of oil formation represents the difference of controlling the remaining oil in water flooding. Or rather, the nearer the interbed is located to the reservoir bottom, the more oil layers with low oil saturation there are. Because the upper subzones in the coarsening-upward reservoir have better physical properties, the injection water flows to 


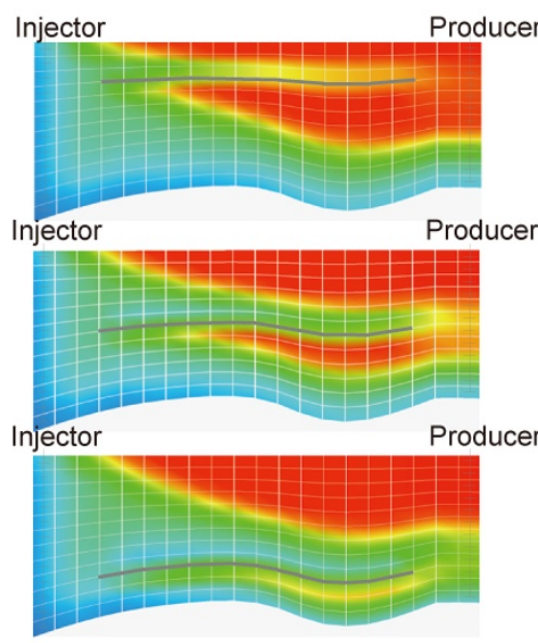

(a) Homogeneous model
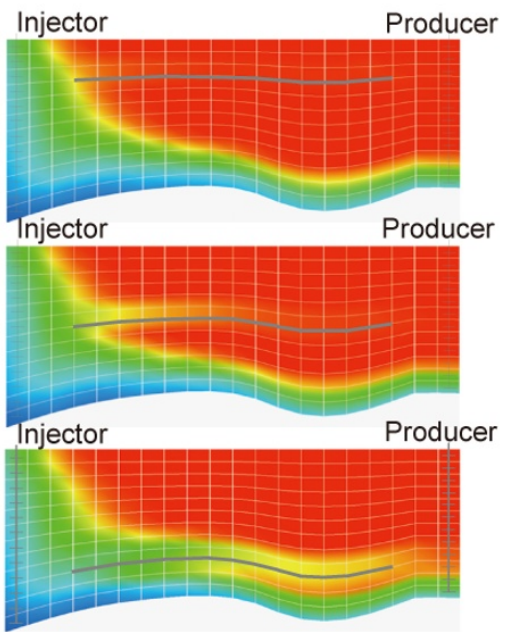

(b) Fining-upward model
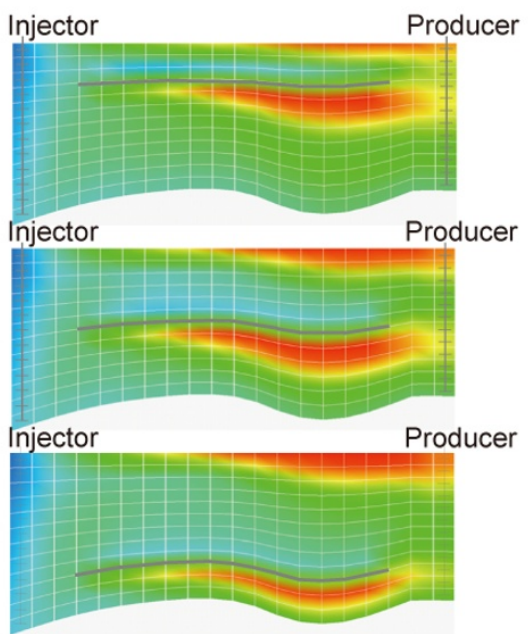

(c) Coarsening-upward model

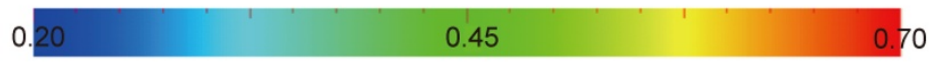

Fig. 4 The distribution pattern of remaining oil after water flooding in models with the interbed present at different vertical locations

the lower subzones with low permeability due to gravity. Therefore, water flooding would achieve better displacement efficiency in coarsening-upward reservoirs than that in finingupward reservoirs and homogenous reservoirs.

Fig. 5 shows the distribution of extra-displaced oil in reservoirs in which the interbed is located $2.25,4.50$ and $6.75 \mathrm{~m}$ from the formation top. It can be seen from Fig. 5: 1) Polymer solution can effectively displace much of the oil remaining in the reservoir after the water flooding operation.
The extra-displaced oil above the interbed is distributed in the upper part of the oil layers while the extra-displaced oil below the interbed is distributed in the bottom part of the formation. 2) Due to the interbed, the extra-displaced oil, which was originally distributed continuously, is divided into an upper part and a lower part, both which take on a spindle shape. 3) The interbed position from the oil formation top affects the discontinuous location of extra-displaced oil in polymer flooding.
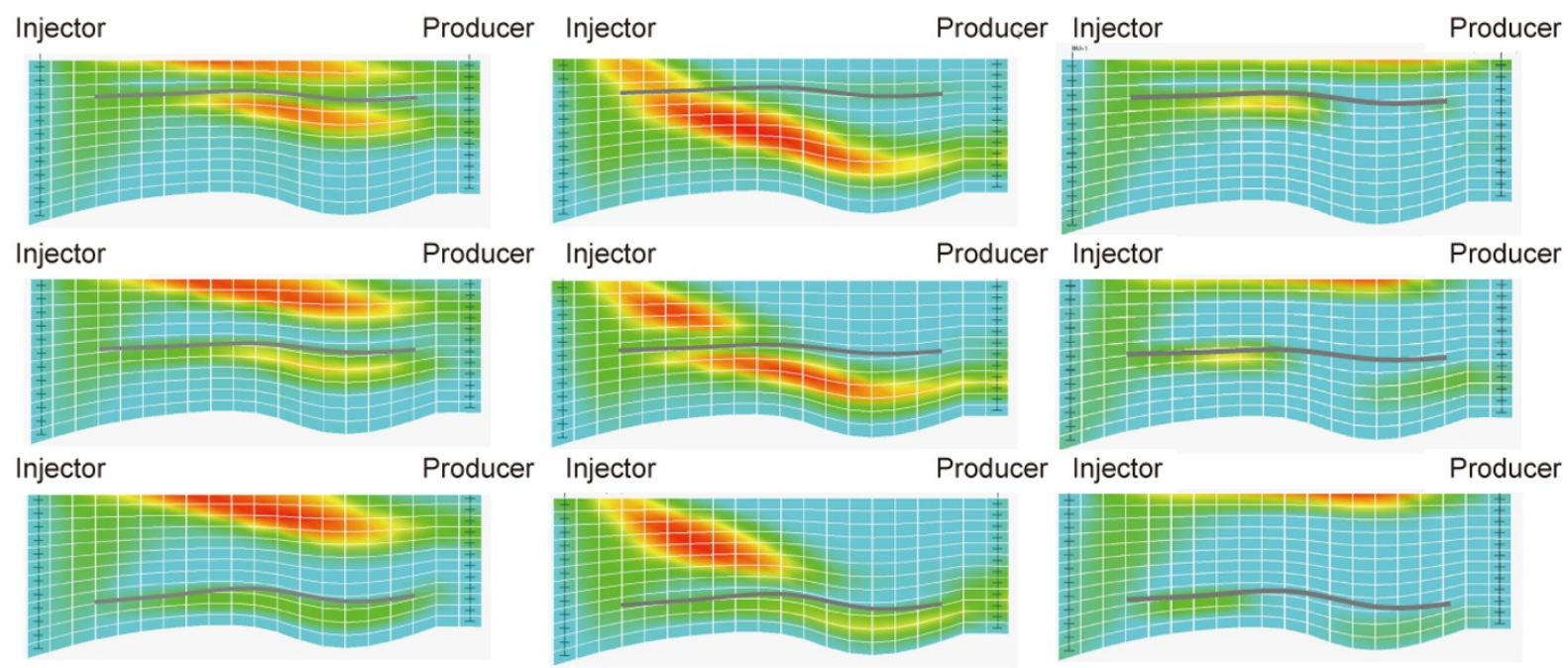

(a) Homogeneous model

(b) Fining-upward model

(c) Coarsening-upward model

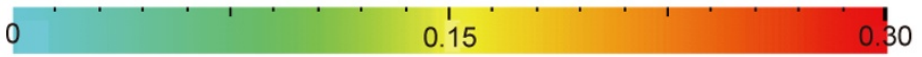

Fig. 5 The distribution pattern of extra-displaced oil in polymer flooding in models with the interbed present at different vertical locations 


\subsection{The effect of the interbed area}

The interbed can effectively inhibit the longitudinal crossflow of injection water as a result of affecting the sweep efficiency. Moreover, the interbed with a long horizontal extension is able to reduce the water flooded area in the bottom reservoir caused by vertical heterogeneity. But it is comparatively weaker for the interbed with a shorter horizontal extension.
Fig. 6 shows the simulation results when the ratio of interbed area to simulation area is respectively $25 \%, 50 \%$, and $75 \%$. The interbed area has a slight influence on the whole distribution shape of extra-displaced oil. A larger interbed area will more strongly inhibit downward cross-flow of injection water. As a result, the effect of water flooding in the upper oil formation of the interbed is very good contributing to high partition extent of the extra-displaced oil in polymer flooding.

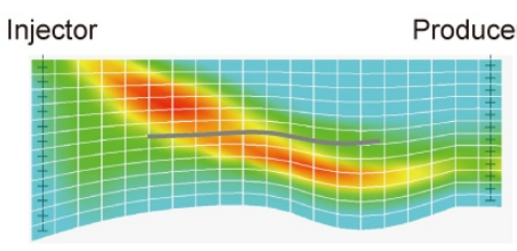

(a) $25 \%$

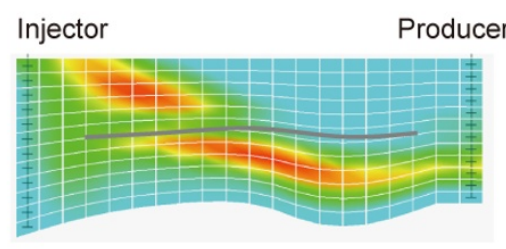

(b) $50 \%$

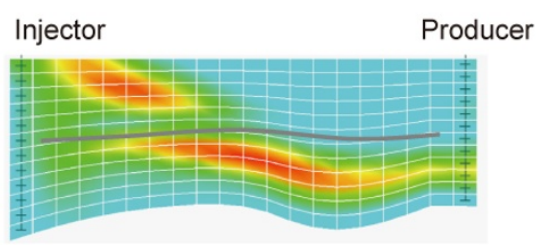

(c) $75 \%$

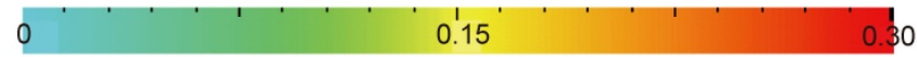

Fig. 6 The distribution of extra-displaced oil in polymer flooding in fining-upward reservoirs interbedded with different-sized interbeds

\subsection{The effect of the interbed permeability}

Interbeds have various permeability values because of their discontinuous distribution and different physical properties. For fining-upward models, the effect of interbed permeability was discussed by varying the vertical permeability of the interbed.
Fig. 7 shows the simulation results when the interbed vertical/horizontal permeability ratio $\left(k_{\mathrm{v}} / k_{\mathrm{h}}\right)$ is $0,0.001,0.05$, and 0.1 , respectively. High interbed vertical permeability contributes to worse partition extent of extra-displaced oil and the partition effect disappears if the $k_{\mathrm{v}} / k_{\mathrm{h}}$ of the interbed is more than 0.05 .

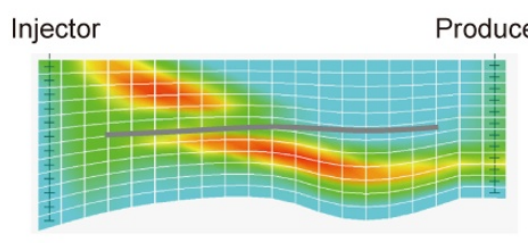

(a) $k_{\sqrt{ }} / k_{\mathrm{h}}=0$

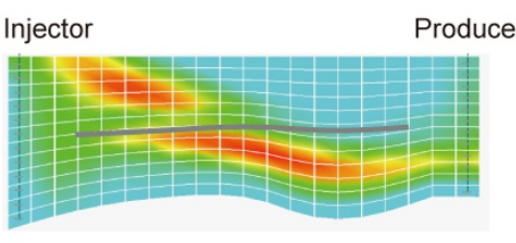

(b) $k_{\mathrm{v}} / k_{\mathrm{h}}=0.001$

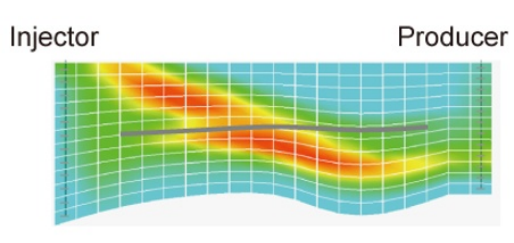

(c) $k_{\mathrm{V}} / k_{\mathrm{h}}=0.01$

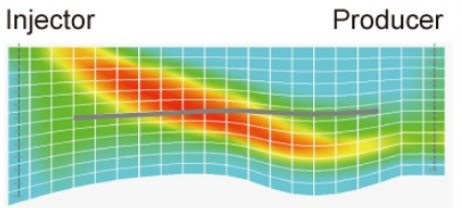

(d) $k_{\mathrm{v}} / k_{\mathrm{h}}=0.05$

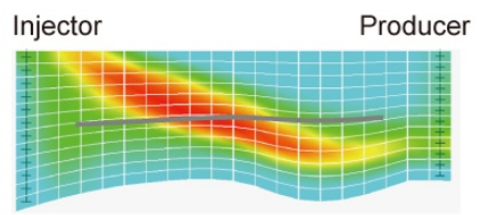

(e) $k_{\mathrm{v}} / k_{\mathrm{h}}=0.1$

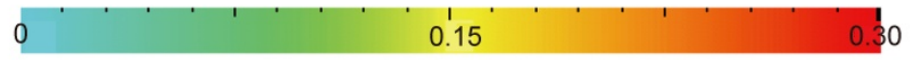

Fig. 7 The distribution of extra-displaced oil in polymer flooding in fining-upward reservoirs with an interbed of different $k_{\downarrow} / k_{\mathrm{h}}$

\section{The effect of the perforation location}

Different planar distribution of the interbed and various shapes of water front advance result in an extraordinarily complicated water flooded situation. Field application of water flooding indicates that if the injection well is drilled through the interbed, a longer interbed is beneficial to the effect of the water flooding in the upper layers. When the length of the interbed within the scope of injection-production distance reaches half of the well spacing, the water advance length in the upper layer will be similar to that in the lower one. However, if the production well is drilled through the 
interbed, the water front will advance along the interbed, leading to a water flooded zone. In addition, a longer interbed easily leads to a larger water flooded zone thickness and the water flooding is less effective in an injection-production group where the interbed is distributed discontinuously. We established three models with different interbed positions, including the injection well drilled through the interbed, the production well drilled through the interbed and the interbed existing between the injection and production wells (Liu and $\mathrm{Xu}, 2003$ ). Taking the interbed horizontal location and well perforation position into consideration, four perforation modes were discussed. They are respectively partial perforation of both the injection and production wells (A), partial perforation of the injection well and complete perforation of the production well (B), complete perforation of the injection well and partial perforation of the production well (C), and complete perforation of both the injection and production wells (D) as shown in Fig. 8. Fig. 9 shows the distribution pattern of extra-displaced oil in polymer flooding under different perforation position.

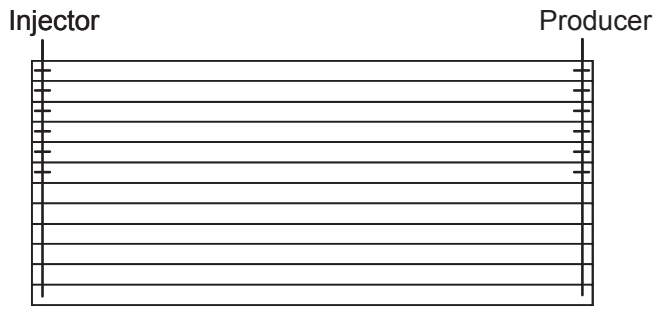

(a) Partial perforation of both the injection and production wells

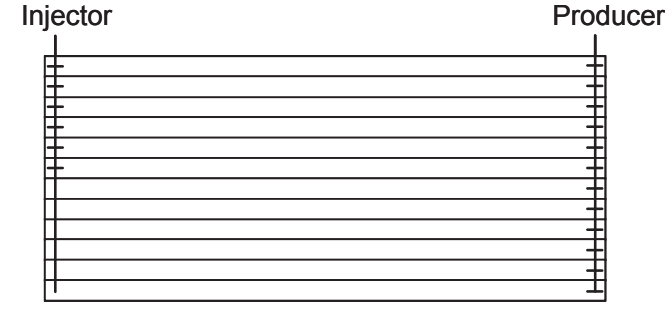

(b) Partial perforation of the injection well and complete perforation of the production well

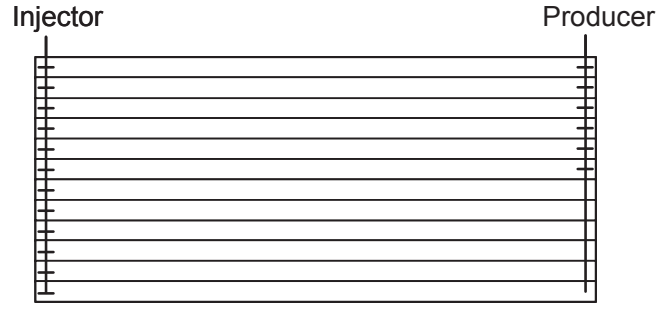

(c) Complete perforation of the injection well and partial perforation of the production well

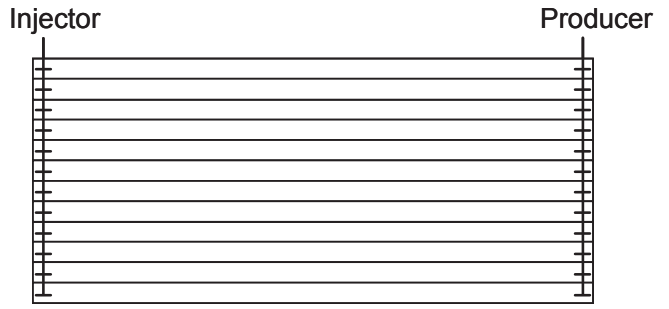

(d) Complete perforation of both the injection and production wells

Fig. 8 Schematic diagram of perforation modes

\subsection{Injection well drilled through the interbed}

The injected water will advance more uniformly when the injection well is drilled through the interbed. This can reduce the influence of gravity, preventing injection water from cross flow downwards and recovering more remaining oil in the upper layers. Simulation results indicate that both water flooding and polymer flooding can obtain satisfactory production performance when the upper part of the injection well is perforated. As for the cases in which the upper part of the injection well and the complete production well are perforated, the remaining oil saturation is the lowest. On the contrary, when the complete injection well and the upper part of the production well are perforated, both water flooding and polymer flooding can also obtain good production performance because this would slow the water coning at a certain extent and delay water breakthrough.

Fig. 9(a) shows the distribution of extra-displaced oil in polymer flooding under different perforation patterns when the injection well is drilled through the interbed. As we can see, when the injection well only above the interbed is perforated, the extra-displaced oil is mainly distributed in the end of the interbed by the side of the production well and the lower part of the reservoir below the interbed. The two parts converge at the end of the interbed, taking on an arrow shape. The extra-displaced oil above the interbed is caused by the profile control of polymer flooding, while the extra-displaced oil below the interbed is displaced and recovered as a result of the pressure drop near the production well. However, when the injection well is completely perforated, the extradisplaced oil is separated into two independent parts, both of which are caused by the profile control of polymer flooding, and the extra-displaced oil below the interbed is closer to the production well.

\subsection{Production well drilled through the interbed}

The injected water will flow separately after it meets the interbed when the production well drills through the interbed. Numerical simulation results show that higher oil recovery can be achieved in water flooding and polymer flooding operations when only the upper part of the production well is perforated. This is mainly because if the production well is completely perforated, the interbed is far away from the 
injection well and would hardly prevent the gravitation of the injection water, leading to a strong downward crossflow and then a watered out well. Conversely, if only the upper part of the production well is perforated, the vertical pressure difference will be relatively high. The injection water will drive the oil upwards after it flows into the reservoir bottom, which is helpful for the oil displacement.

Fig. 9(b) shows the distribution of extra-displaced oil in polymer flooding when the production well is drilled through the interbed with different perforation patterns. As we can see, if the production well is perforated completely, the interbed has a slight influence on the oil displacement. More polymer solution flows into high permeability zones in the lower part of the reservoir, and the polymer would plug the high permeability zones. This is helpful to displace the remaining oil effectively. However, if only the upper part of the production well is perforated, the polymer solution flows into the high permeability zone at the lower part of the reservoir. It is disadvantageous to the displacement of oil below the interbed and only the oil above the interbed is displaced, with a small amount of extra-displaced oil.
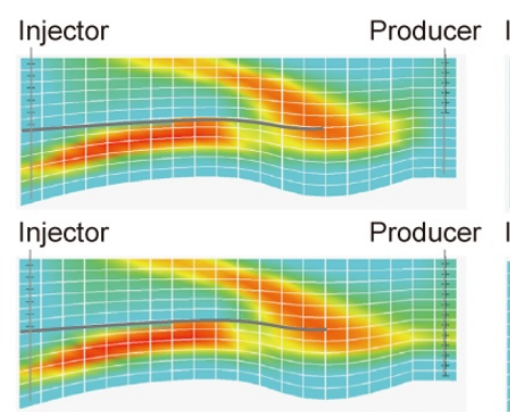

Injector

Producer Injector
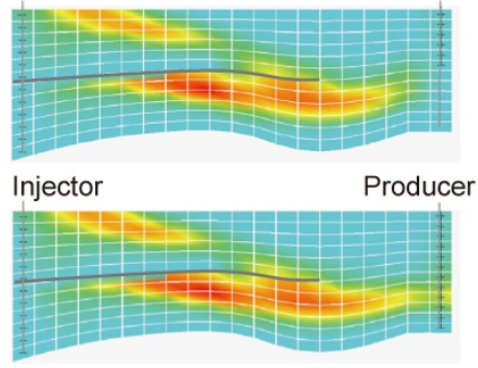

(a) Injection well drilled through the interbed

Injector

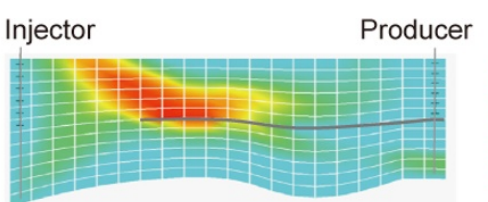

Producer Injector
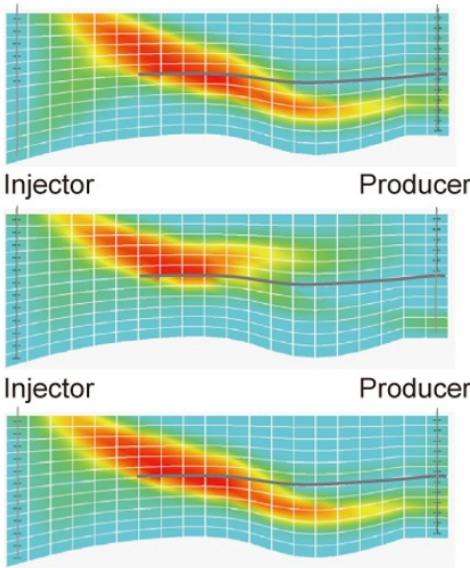

(b) Production well drilled through the interbed
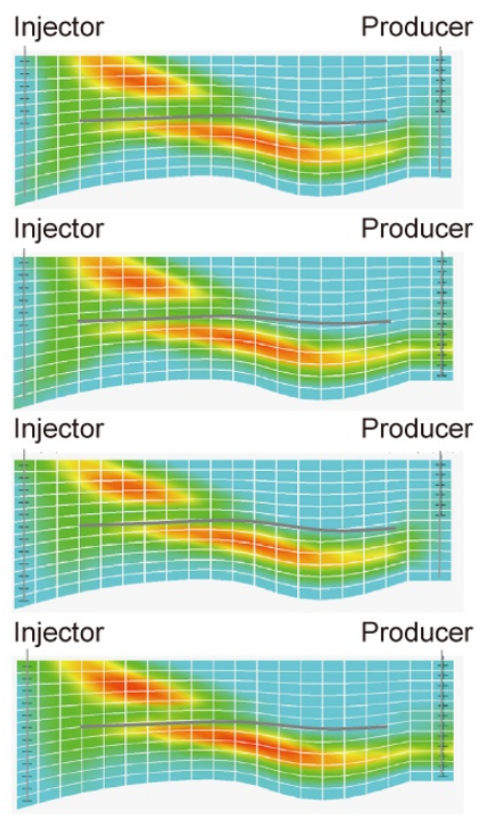

(c) Interbed existing between the injection and production wells

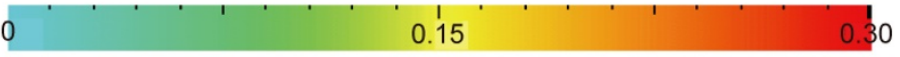

Fig. 9 The distribution pattern of extra-displaced oil with the varied perforation location relative to the interbed

\subsection{Interbed existing between the injection and production wells}

The diversionary function of the interbed is relatively weak when the interbed exists only between the injection and production wells. Numerical simulation results show that the interbed has a slight influence on the production performance in the water flooding and polymer flooding operations, while it has a significant influence on the distribution of extra-displaced oil in the polymer flooding operation. The distribution of extra-displaced oil in polymer flooding (Fig. 9(c)) shows that the oil displaced by the polymer solution is closer to the production well when the production well is perforated completely compared with the well perforated only in the upper part of the oil layer.

\subsection{Comprehensive comparison of polymer displacement efficiencies}

Fig. 10 shows the remaining oil saturation after polymer flooding and Fig. 11 shows the extra-displaced oil saturation in polymer flooding in different interbed positions and different perforation patterns. There are four perforation modes (as shown in Fig. 8) in Figs. 10 and 11.

Figs. 10 and 11 indicate that if the injection well is drilled through the interbed and the injection well is perforated in the upper layer, displacement efficiency would be the highest. As a result, the remaining oil saturation is the lowest and the extra-displaced oil saturation is the highest (more than 0.07). While if the interbed exists between the injection and production wells, relatively low ultimate recovery will be 


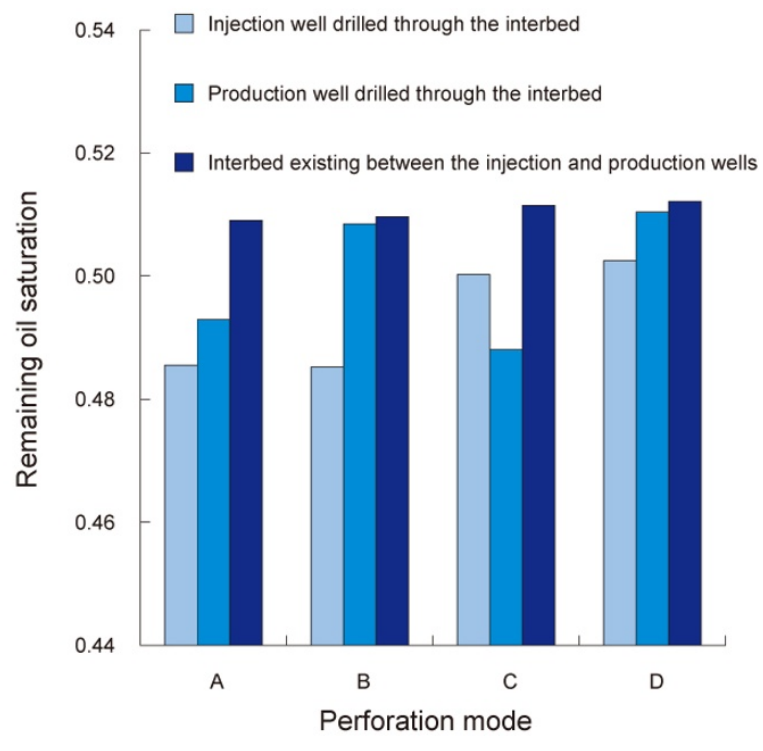

Fig. 10 The influence of the perforation location relative to the interbed on remaining oil after polymer flooding

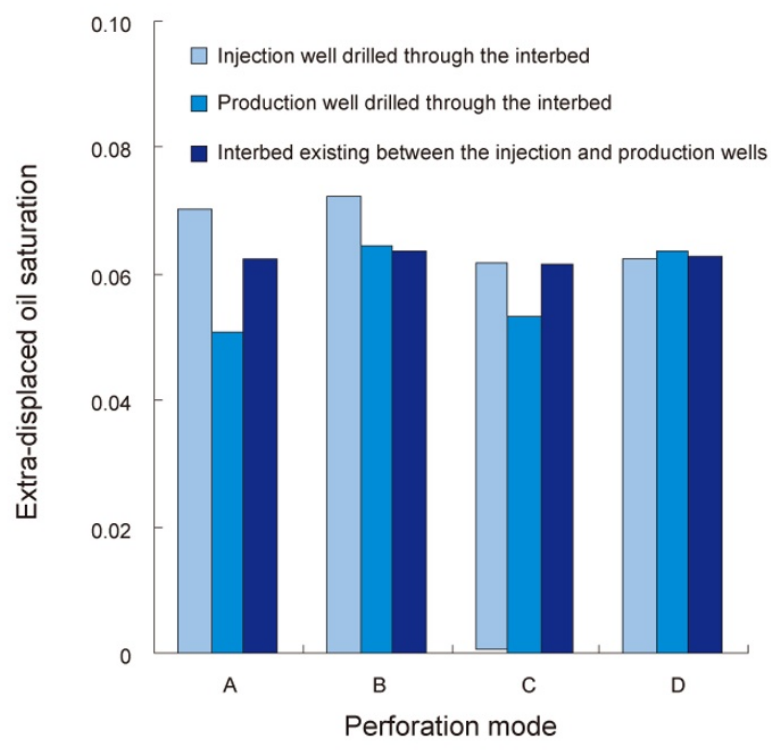

Fig. 11 The influence of the perforation location relative to the interbed on extra-displaced oil in polymer flooding

achieved in polymer flooding and the remaining oil saturation is higher. However, the extra-displaced oil saturation, which is more than 0.06 , in polymer flooding is relatively high.

\section{Conclusions}

1) Based on the Ng3 unit in Zhongyi area, Gudao oilfield, in which polymer flooding has been used as an enhanced oil recovery technique, a detailed simulation model has been established. The influence of the perforation location relative to the interbed on the macroscopic distribution of extradisplaced oil in polymer flooding was discussed.

2) The interbed has the function of separating extradisplaced oil in polymer flooding. The interbed position from the oil formation top affects the discontinuous location of extra-displaced oil. The interbed area has a slight influence on the whole distribution shape of extra-displaced oil. Higher interbed vertical permeability contributes to a worse partition extent of extra-displaced oil.

3) The perforation location relative to the interbed affects the polymer displacement efficiency and also has a significant effect on the distribution of extra-displaced oil in polymer flooding.

\section{Acknowledgements}

The authors are grateful for the financial support from the National Natural Science Foundation of China (No. 10772200, 10972237) and the Important National Science \& Technology Specific Projects of China (No. 2011ZX05011).

\section{References}

Chang H L, Zhang Z Q, Wang Z S, et al. Advances in polymer flooding and alkaline/surfactant /polymer processes as developed and applied in the People's Republic of China. Journal of Petroleum Technology. 2006. (2): 84-89

Chen $\mathrm{C}$ and Sun Y M. The distribution patterns of the interlayer within thick pays and their impact on recovery efficiency. Petroleum Geology \& Oilfield Development in Daqing. 2003. 22(2): 24-27 (in Chinese)

Du Q J, Chen Y M and Hou J. Control of interlayer on the distribution of remaining oil in thick reservoirs of Shengtuo Oilfield. Journal of Oil and Gas Technology. 2006. 28(4): 111-114 (in Chinese)

Hou J, Du Q J, Shu Q L, et al. Macroscopic response mechanism and distribution rules of remaining oil in polymer flooding. Acta Petrolei Sinica. 2010. 31(1): 96-99 (in Chinese)

Hou J, Guo L L, Yuan F Q, et al. Quantitative characterization of polymer flooding production performance in different reservoirs of Shengli Oilfield. Acta Petrolei Sinica. 2008. 29(4): 577-581 (in Chinese)

Hou J G. Prediction of interbeds intercalated into complex heterogeneous reservoirs at a high water cut stage. Petroleum Science. 2007. 4(3): 26-30

Jupiter C R. Reservoir simulation leads to determination of location of remaining oil and successful drilling in the Guapo thermal scheme, Trinidad. Paper SPE 133536 presented at the Trinidad and Tobago Energy Resources Conference, 27-30 June 2010, Port of Spain, Trinidad

Liu J M and Xu S Y. Reservoir sedimentary model of fluvial facies and its control on remaining oil distribution. Acta Petrolei Sinica. 2003. 24(1): 58-62 (in Chinese)

Sun H Q. Practice and understanding on tertiary recovery in the Shengli Oilfield. Petroleum Exploration and Development. 2006. 33(3): 262266 (in Chinese)

Wang D M, Cheng J C, Wu J Z, et al. Experiences learned after production more than 300 million barrels of oil by polymer flooding in Daqing Oil field. Paper SPE 77693 presented at SPE Annual Technical Conference and Exhibition, 29 September-2 October 2002, San Antonio, Texas

Wang D M, Zhao L S, Cheng J C, et al. Actual field data show that production costs of polymer flooding can be lower than water flooding. Paper SPE 84849 presented at SPE International Improved Oil Recovery Conference in Asia Pacific, 20-21 October 2003, Kuala Lumpur, Malaysia

(Edited by Sun Yanhua) 